\title{
Launching a Research Initiative: The Canadian Pediatric Epilepsy Network (CPEN)
}

\author{
Sharon Whiting, Peter Camfield, Samuel Wiebe, Maryse Lassonde, \\ Hannelore Sauerwein, Lionel Carmant
}

\begin{abstract}
The Canadian Pediatric Epilepsy Network is a network of scientists and health care professionals in partnership with organizations which provide education and support to children with epilepsy. The objective of the network is to gain a better understanding of childhood epilepsy through collaborative research conducted with doctors, psychologists, nurses, social workers, educators and scientists across Canada. The network was launched at a meeting in Ottawa in the spring of 2000 where several oral presentations addressed the issues of the fundamental questions of epilepsy, the economic impact and the neuropsychology of childhood epilepsy. The intent was to provoke discussion on future areas of research for the network.
\end{abstract}

RÉSUMÉ: Lancement d'une initiative de recherche: le Réseau canadien de la pédiatrie et de l'épilepsie. Le Réseau canadien de la pédiatrie et de l'épilepsie est un réseau de chercheurs et de professionnels de la santé agissant en partenariat avec des organismes d'éducation et de soutien aux enfants épileptiques. L'objectif de ce réseau est d'acquérir une meilleure compréhension de l'épilepsie chez l'enfant par la recherche effectuée en collaboration à travers le Canada par des médecins, des psychologues, des infirmières, des travailleurs sociaux, des éducateurs et des chercheurs. Le réseau a été lancé au printemps 2000, lors d'une réunion à Ottawa où plusieurs présentations orales ont traité de questions fondamentales en épilepsie ainsi que de l'impact économique et de la neuropsychologie de l'épilepsie chez l'enfant. L'objectif était de susciter la discussion sur les avenues de recherche du réseau.

Can. J. Neurol. Sci. 2002; 29: 364-371

The Canadian Pediatric Epilepsy Network (CPEN) was developed after receiving a grant from the Canadian Institute of Health Research in the fall of 1999 entitled "Towards a multidisciplinary approach to pediatric epilepsy in Canada". This network is comprised of a group of researchers involved in the study of various aspects of epilepsy as it affects children. We hope to gain a better understanding of childhood epilepsy through a collaborative research program involving physicians, nurses, psychologists, epidemiologists, social workers, basic scientists and educators across Canada.

This paper represents a review of several aspects of pediatric epilepsy synthesizing the current status of the disorder. These were presented orally at the inaugural meeting of CPEN in April 2000 in Ottawa.

The review is in three sections, the first dealing with fundamental questions of epilepsy ranging from an accurate definition to treatment opinions (Dr. Camfield). The burden of epilepsy for the person, family and the community at large is discussed in the second section (Dr. Wiebe), followed by an overview of the cognitive consequences associated with childhood epilepsy in the third (Drs. Sauerwein, Lassonde and Carmant).
SECTION 1: WHERE ARE WE IN PEDIATRIC EPILEPSYAND WHERE DO WE NEED TO GO?

A critical review of treatment for childhood epilepsy raises many issues. This review focuses on questions that must be addressed as we advance the quality of treatment for children with epilepsy - What is epilepsy? What is the value of an epilepsy syndrome diagnosis? Which antiepileptic drugs (AEDs) are most effective? How long should treatment be continued? When can intractable epilepsy be recognized? What is the adult social outcome of childhood onset epilepsy?

A fundamental unsettled question is - What is epilepsy? There is consensus that after a first unprovoked seizure, $40-50 \%$ of children will have a recurrence. ${ }^{1,2}$ After a second seizure the risk of a third rises to $\sim 80 \% .^{3}$ The concept of epilepsy implies a

From the University of Ottawa, Ontario (SW), Dalhousie University, Halifax, Nova Scotia (PC), University of Western Ontario, London, Ontario (SW), l'Université de Montréal, Montreal, QC (ML, HS, LC), Canada.

ReCEIVEDMAy 22, 2001. ACCEPTEDIN FINALFORMmay 15, 2002.

Reprint requests to: Sharon Whiting, Division of Neurology, Children's Hospital of Eastern Ontario, 401 Smyth Road, Ottawa, Ontario, K1H 8L1 Canada. 
recurrent disorder. Two unprovoked seizures are accepted as necessary for the diagnosis even though $20 \%$ of those with two will have no more.

How do we know that seizures have occurred? Eventually there may be biologic indicators that reliably identify the effects of a seizure. Currently we nearly always rely on the parent's description but the reliability of these histories has not been carefully assessed. A group of Dutch neurologists reviewed abstracted case histories and had quite good agreement on which children had epilepsy and which had nonepileptic paroxysmal events. ${ }^{4}$ Reading case abstracts, however, is not the same as hearing the actual history. Further study with videotaped interviews or programmed patients might be closer to the "real thing". We need to know if epilepsy experts and nonexperts agree that a seizure has occurred. Unfortunately, nothing short of an ictal EEG can definitively indicate that a seizure has occurred. Spike discharge on interictal EEG may occur in children without seizures. Home video may be of use but still requires clinical interpretation.

Once the diagnosis of a seizure disorder is made, we now insist that there is further value in defining the child's epilepsy syndrome. It is suggested that the syndrome diagnosis determines the best treatment and most accurate prognosis. ${ }^{5}$ For a few syndromes, this contention seems correct. For example, a confident diagnosis of typical benign rolandic epilepsy suggests which AEDs will be useful and guarantees a favourable longterm outcome. The diagnosis of severe myoclonic epilepsy of infancy means that seizure control will not be achieved and the child will be mentally handicapped. ${ }^{6}$ However, a diagnosis of many other syndromes has limited power to predict remission. Fifty-sixty percent of children with cryptogenic partial epilepsy remit, which is marginally better than symptomatic partial epilepsy. ${ }^{7}$ Of children with childhood absence epilepsy, $15 \%$ later develop juvenile myoclonic epilepsy with a life long need for treatment. ${ }^{8}$ Better understanding of the biologic mechanisms of various syndromes may help to understand variable prognosis within a given syndrome or redefine more homogenous syndromes.

There are a few genetic epilepsy syndromes where the biochemical genetic basis has been identified. Even here, heterogeneity of clinical expression is the rule. A good example is Generalized Epilepsy with Febrile Seizures Plus (GEFS+). ${ }^{9}$ This disorder is inherited as autosomal dominant and is the result of a defect in neuronal voltage-gated sodium channels. A tremendous variety of seizure and epilepsy types appear in these kindreds, even though each affected member has the same genetic defect.

Once a syndrome is diagnosed, most childhood epilepsy is treated with daily AEDs. All large comparative trials of different AEDs for newly diagnosed epilepsy have had similar results about $50-70 \%$ of children with epilepsy respond to the first prescribed AED, whichever one it is! The only drug to fall by the wayside has been phenobarbital, based on behavioural side effects. ${ }^{10}$ Otherwise, clobazam, carbamazepine, phenytoin, valproic acid, lamotrigine and vigabatrin all have similar efficacy. ${ }^{11-14}$ Randomized trials comparing medications in specific syndromes are virtually nonexistent. Our French colleagues are to be congratulated for carrying out a double-blind trial of stiripentol for Severe Myoclonic Epilepsy of Infancy. ${ }^{15}$
This uncommon but important syndrome was proven to respond to a nontraditional AED. All newer AEDs have been compared with placebo, a study design that is required by government regulators prior to licensing but has little relevance for clinicians with a choice of drugs. Only comparative trials can unequivocally advance our choice of AEDs for a given syndrome.

When daily treatment is begun and the first AED is unsuccessful in controlling the seizures, there is a sense of doom $;{ }^{16}$ however, our experience suggests that the majority of children who fail treatment with the first AED will still achieve remission. ${ }^{17}$ Newer AEDs tend to be started in refractory patients and in general have been disappointing. To help resistant pediatric patients, a different form of AED development is needed. The current animal models do not predict well which drug will be most helpful in which type of epilepsy. Only two AEDs have been discovered by rational biochemistry vigabatrin and tiagabine. Both drugs increase brain gamma amino butyric acid. It is sobering to realize that vigabatrin was not recognized as having any anti-epileptic properties when initially screened because the effect requires a longer introduction than the usual current AED animal screening protocol. Sadly, retinal problems have limited the usefulness of vigabatrin but there is no doubt about its potency as an AED. ${ }^{18}$ Tiagabine does not appear to be as effective as initially hoped although it does not seem to show the same retinal toxicity. ${ }^{19}$

Some children outgrow their epilepsy and after a period of treatment with AEDs, are able to successfully "come off" medication. How long should children be treated? This issue has been extensively researched and the very the thoughtful review of Berg and Shinnar summarizes the literature thoroughly. ${ }^{20}$ One-year seizure-free with monotherapy is successful in 60$70 \%$, about the same percentage as two, three or five years. ${ }^{20,21}$ Only two randomized trials have addressed length of treatment. In one, children with quick response to their initial medication were randomized to six months or one year of treatment. ${ }^{22}$ Although long-term remission was the same in both groups, six months treatment had more relapses than 12 months. In the other study, treatment for one year was compared with three years. ${ }^{23}$ The three-year group had fewer relapses. Neither study approached the issue of the psychosocial impact on the child and family. Since there is good evidence that AEDs do not alter longterm prognosis, the rationale for different treatment regimes must be partly based on factors other than seizure frequency. ${ }^{24}$

Intractable childhood epilepsy is a big problem. We need a working definition that is syndrome specific, objective and easily recognized. Currently there is no agreed upon definition. We need to know that if a child's epilepsy is said to be refractory, other AEDs are exceedingly unlikely to be effective. Rather than trying 15 different AEDs, we should be able to move earlier to other treatments such as surgery, the ketogenic diet or the vagus nerve stimulator. ${ }^{25}$

The social outcome of childhood epilepsy is not guaranteed to be good, even if the epilepsy remits. One study compared the social outcome in young adulthood of childhood absence epilepsy with juvenile rheumatoid arthritis as a chronic disease control. ${ }^{26}$ Social outcome in Childhood Absence was much less favourable. In another population based study, nearly one-half of children with partial or generalized tonic clonic seizures had 
Table 1: Annual costs per patient in prevalent cases

\begin{tabular}{|c|c|c|c|c|}
\hline Study & Country, Year & Direct costs \$ & Indirect costs \$ & Total costs \$ \\
\hline Gessner et $\mathrm{al}^{32}$ & Switzerland, 1993 & 14,400 & 7,900 & 22,300 \\
\hline Cockerell et al ${ }^{31}$ & UK, 1994 & 4,000 & 9,200 & 13,200 \\
\hline Banks, Beran et al ${ }^{30}$ & Australia, 1995 & 4,200 & 5,200 & 9,400 \\
\hline Murray et al ${ }^{46}$ & USA, 1994 & 4,600 & 14,400 & 19,000 \\
\hline Begley et $\mathrm{al}^{35}$ & USA, 2000 & 1,100 & 7,200 & 8,300 \\
\hline
\end{tabular}

Estimated costs are in 2001 Canadian dollars

unfavourable social outcomes 8-10 years after diagnosis. ${ }^{27} \mathrm{~A}$ study from Finland followed children with epilepsy for 35 years. Life satisfaction and employment was not satisfactory for many whose only handicap was epilepsy. ${ }^{28}$ We need to think of childhood epilepsy as a disorder that will have effects on adult social function. We need to understand why and what to do about it.

Clearly there is a huge amount of work left to be done to solve the riddles of childhood epilepsy. Hopefully young investigators will be drawn to the specialty of pediatric epilepsy.

\section{SECTION 2: THE BURDEN OF EPILEPSY}

The burden of chronic illnesses like epilepsy is multifactorial and should be assessed for several reasons. First, it provides a broader picture of the clinical problem and provides a framework of relevance for research initiatives. Second, it provides important background information for researchers approaching funding agencies and for health care providers submitting proposals to health care agencies and institutions. Third, it may help identify areas on which research should focus. There are no comprehensive studies of the burden of epilepsy. However, investigators have explored individual aspects of the burden of epilepsy that allow us to draw a reasonably accurate picture of this construct.

\section{What is the cost of epilepsy?}

A review of the literature identifies six national studies of the cost of epilepsy. One from Australia, ${ }^{29,30}$ one from the UK, ${ }^{31}$ one from Switzerland, ${ }^{32}$ and three from the USA. ${ }^{33-35}$ No similar studies have been done in Canada. The economic cost of illness is typically measured in terms of direct costs (medical and nonmedical resources used in the management of patients with epilepsy) and indirect costs (the loss of productivity due to epilepsy). Table 1 shows (in 2001 Canadian dollars) that in different studies, the estimated direct annual costs per patient range from $\$ 1,100$ to $\$ 14,400$, and the indirect costs range from $\$ 5,200$ to $\$ 14,400$. The cost of epilepsy in different studies varies broadly because of differences in methods, populations, and socioeconomic contexts. Begley et $\mathrm{a}^{36}$ provide a detailed review of the methodological differences in these studies.

How does the cost of epilepsy compare to that of other common health problems? This depends on the health care system and societal context. In North America, investigators have estimated a lifetime cost of CAN $\$ 35.5$ billion for cancer, CAN\$22.2 billion for motor vehicle accidents, CAN\$21.1 billion for ischemic heart disease, ${ }^{37}$ as compared with CAN\$17.1 billion for epilepsy ${ }^{35}$ and CAN\$11.2 billion for stroke. ${ }^{38}$

Begley et $\mathrm{al}^{35}$ performed the most recent, comprehensive cost of epilepsy study in the USA. They examined the lifetime costs associated with treating patients from the onset of the diagnosis, as well as the annual costs of treating existing (prevalent) cases of epilepsy. Although we acknowledge that there are important differences in health care systems and in medical practice between Canada and the USA, the study by Begley et al may provide an approximate outline of what the cost of epilepsy may be in Canada. The total lifetime costs for new cases of epilepsy in the USA were CAN $\$ 17.1$ billion and the annual costs of treating all existing cases of epilepsy reach CAN\$19.2 billion. It is of interest that, in this study, indirect costs (foregone earnings and productivity) vastly surpass direct costs (medical and nonmedical care) (Table 1). This predominance of indirect costs is in keeping with the distribution of costs in other chronic conditions. ${ }^{37}$ Table 2 demonstrates that in the study by Begley et al, the direct lifetime costs of new cases of epilepsy (CAN\$2.7 billion) were similar to the annual costs of existing cases of epilepsy (CAN\$2.6 billion) in the USA; and that the largest cost components in both populations were hospital and anticonvulsants, each accounting for almost one third of the total costs.

The cost of illness varies with the clinical characteristics of

Table 2: Direct medical costs of epilepsy in the USA*

\begin{tabular}{lcc}
\hline & $\begin{array}{c}\text { Lifetime cost of } \\
\text { new cases } \\
(\%)\end{array}$ & $\begin{array}{c}\text { Annual cost of } \\
\text { existing cases } \\
(\%)\end{array}$ \\
Hospital & $808.6(31)$ & $864.2(33)$ \\
Anticonvulsants & $788.8(29)$ & $804(31)$ \\
Diagnostics & $580.8(22)$ & $494.5(21)$ \\
Physicians & $328.9(12)$ & $281.8(11)$ \\
Surgery & $190.5(7)$ & $163.7(6)$ \\
Total & $2,698.5(100)$ & $2,595.4(100)$
\end{tabular}

*In millions of 2001 Canadian dollars. Based on data from Begley et a ${ }^{35}$ 
Table 3: The burden of epilepsy in Canada

\begin{tabular}{|c|c|c|c|c|}
\hline & Healthy & $\begin{array}{c}\text { General } \\
\text { Population }\end{array}$ & $\begin{array}{c}\text { Chronically } \\
\text { Ill }\end{array}$ & Epilepsy \\
\hline \multicolumn{5}{|l|}{ Quality of Life (mean $\pm 95 \%$ CI)* } \\
\hline & $32.5 \pm 0.2$ & $31.4 \pm 0.1$ & $31.0 \pm 0.2$ & $26.1 \pm 0.2$ \\
\hline \multicolumn{5}{|l|}{ Family Function` (\%) } \\
\hline Dysfunctional family & 20.9 & 21.6 & 21.9 & 27.5 \\
\hline \multicolumn{5}{|l|}{ Social Support (mean $\pm 95 \%$ CI) $\dagger$} \\
\hline Low Annual Income (\%) & - & 13.7 & 14.5 & 22.2 \\
\hline \multicolumn{5}{|l|}{ Use of medical services (\%) } \\
\hline Emergency Room & 13.6 & 22.5 & 27.1 & 35.6 \\
\hline Hospital admission & 6.7 & 11.8 & 14.5 & 22.4 \\
\hline Psychologist/Counsellor & 2.1 & 4.1 & 5.2 & 14.8 \\
\hline
\end{tabular}

*Higher scores = better quality of life using the Psychological General Well Being scale

- Higher scores = worse family function using the Family Assessment Device

$\dagger$ Higher scores $=$ stronger social support using the Social Support Index

$\ddagger<$ CAN\$22,000 per year per household

From Wiebe S, Bellhouse DR, Fallahay C, Eliasziw M. Burden of epilepsy: the Ontario Health Survey. Can J Neurol Sci 1999;26:265 with permission.

epilepsy. Two studies in the $\mathrm{UK}^{31,39}$ found that the cost of epilepsy was eight to ten times higher in those with active epilepsy, and in one of these studies ${ }^{39}$ the costs were twice higher in patients with $\geq 1$ monthly seizure, as compared with patients with $<1$ monthly seizure. This underscores the role of optimum seizure control in reducing the burden of epilepsy.

\section{The burden of epilepsy in Canada}

In Canada, the burden of epilepsy in the community can be gleaned from the 1994 Ontario Health Survey, which provides data on over 61,000 members of the general population. ${ }^{40}$ The survey yielded a point prevalence of self-reported epilepsy of 5.8 per 1,000, which is similar to that of other countries. ${ }^{41}$ It also revealed that epilepsy imposes a significant burden on the patients and on society. As compared with persons suffering from other chronic health conditions, such as arthritis, diabetes, and respiratory diseases, people with epilepsy had significantly poorer quality of life, lower levels of social support, poorer family function and social support, and lower household income (Table 3). In addition, epilepsy sufferers had more disability days, resulting in an estimated yearly productivity loss of \$139 million in Ontario. Similarly, persons with epilepsy required more services from medical specialists, family doctors, nurses and counsellors; and they used more health care resources, emergency services, and hospital admissions than those with other chronic conditions (Table 3 ). ${ }^{40}$

Extrapolating from the analysis of the cost of epilepsy in the USA by Begley et al, ${ }^{35}$ the estimated annual cost of epilepsy in Canada would be about CAN\$1.92 billion, of which CAN\$1.65 billion correspond to indirect costs (foregone earnings due to morbidity and mortality), and CAN $\$ 27$ million to direct costs. The latter figure does not include nonmedical costs such as social, volunteer and counselling support, which in the Canadian population account for $10 \%$ to $20 \%$ of direct costs. ${ }^{42}$ Nor does it include disability and unemployment payments, which although significant, are not seen as costs but as transfer payments, in economic analyses.

\section{The cost-effectiveness of epilepsy therapy in Canada}

Few cost effectiveness studies of epilepsy interventions have been done in Canada. This is important because the cost effectiveness ratios of an intervention may vary substantially among different health care systems. This is determined by differences in clinical practice, and prices and quantities of resources used in an individual therapy. In the Canadian health care system, epilepsy surgery in selected patients with refractory temporal lobe epilepsy has been shown to be more efficacious and cheaper than medical therapy in adults ${ }^{42}$ and in children. ${ }^{43}$ Although surgical costs are higher in the first year, cumulative costs are equal by the eighth and fourteenth year of treatment in adults and children, respectively, and medical therapy remains more expensive thereafter. In 1993, the average annual direct medical and nonmedical costs per patient were CAN\$3,000 with medical therapy and CAN $\$ 2,300$ with surgery. ${ }^{42}$ The costeffectiveness of other surgical and nonpharmacological interventions remains to be determined. Finally, in the first randomized controlled trial of epilepsy surgery, Canandian researchers have demonstrated the incontrovertible superiority of surgical therapy for temporal lobe epilepsy, thus confirming the effectiveness and efficiency of this therapy. ${ }^{44}$ 


\section{The global burden of epilepsy}

Epilepsy remains uncontrolled in about $30 \%$ of patients whose cost of illness is about 12 times higher than in those with controlled epilepsy. Moreover, quality of life is worse in persons with uncontrolled than with well-controlled epilepsy. ${ }^{45}$ These facts stress several points. First, seizure control is an important determinant of the burden of epilepsy with regards to cost and quality of life. Second, effective epilepsy therapy can improve quality of life and reduce the economic and psychosocial burden of epilepsy. And third, research into more efficacious therapies is needed.

That epilepsy imposes a significant burden on the world population is recognized by the World Health Organization, which established that epilepsy is the world's second leading cause of disability among mental health disorders. ${ }^{46}$ Unfortunately, it has also been demonstrated that research funds are not necessarily allocated on the basis of burden of illness ${ }^{47}$ and that support for epilepsy research is deficient in Canada (W.T. Blume, personal communication) and abroad ${ }^{48}$ Concerted efforts such as the CPEN are essential to help close the gap between burden of illness and research support in epilepsy.

\section{SECTION 3: Cognitive AND BEHAVIOURAL CONSEQUENCES OF CHILDHOOD EPILEPSY: THE PREVAILING VIEW}

Childhood epilepsy constitutes one of the most prevalent forms of chronic and disabling childhood illnesses. Indeed, one child out of 20 experiences one or more seizures before the age of five, and one in 100 develops epilepsy as a chronic disorder. ${ }^{49}$ Many of these children exhibit academic difficulties and/or behavioural disorders which will result in a lower quality of life. ${ }^{50-52}$ Moreover, there is reason to believe that a sizeable proportion of children with learning disabilities suffer from undiagnosed epilepsy. These are children who have subclinical discharges in the absence of obvious disruption of consciousness. ${ }^{53}$ The epileptiform activity interferes with perceptual and motor performances, causing transitory cognitive impairments. The kind and magnitude of these impairments depend on the morphology of the epileptiform activity. For instance, generalized spike-wave discharges seem to have a greater impact on cognitive performances than lateralized focal spike-wave discharges, although the latter can cause transitory disruption of the functions that are subserved by the affected region. ${ }^{53}$

In adult patients different types of epilepsies have been associated with specific impairments related to the site and laterality of the abnormality. ${ }^{54,55}$ However, childhood epilepsy, because of its interference with brain maturation, has long been thought to produce diffuse, nonspecific dysfunction such as mental deficiency, behaviour problems and psychiatric disorders. Indeed, classical reports indicate that behavioural and psychiatric disorders are two to three times more frequent in epileptic children than in healthy controls and children with other chronic disorders. ${ }^{56-58}$ Irritability, impulsiveness, hyperactivity, aggressiveness, anxiety, depression and a variety of maladaptive behaviours have been reported. ${ }^{59,60}$ In the seminal study conducted on the Isle of Wight, ${ }^{57} 29 \%$ of children with uncomplicated epilepsy displayed psychiatric problems as compared to $12 \%$ of children with non-neurological chronic diseases. By the same token, adults with childhood onset of epilepsy have been found to be two to three times more likely to manifest psychiatric and/or social adjustment problems than control populations. ${ }^{61}$

Other studies have shown that the intellectual quotient (IQ) of epileptic children is lower than that of the general population. ${ }^{62}$ In fact, it has been estimated that up to $14 \%$ of epileptic children have an IQ in the mentally deficient range. ${ }^{53}$ By the same token, learning disabilities are known to be overrepresented in the epileptic population and this includes children with normal intelligence ${ }^{63-65}$ and "benign" forms of epilepsy. ${ }^{66,67}$ Studies in heterogeneous samples of epileptic children with normal or near normal IQ have consistently shown that these children tend to progress at a slower rate than would be predicted on the basis of their general cognitive abilities. ${ }^{50,68}$ Prospective data further suggest that only a relatively small proportion of these patients go on to secondary education and hold academic positions. ${ }^{50,69}$ Evidently, children with lower cognitive abilities and/or more severe forms of epilepsy are at greater risk of developing learning problems. Thus, Aldenkamp et $\mathrm{al}^{70}$ found that $30 \%$ of children with therapy-resistant epilepsy required special education compared to $7 \%$ of children in a control group without neurological disease. Again the cognitive problems are generally believed to be the nonspecific consequences of the impact of abnormal brain activity on attention, memory and performance speed. ${ }^{71,72}$

Collectively, these findings have been taken as evidence that, unlike in adults, epilepsy in children produces global disturbances in cognition and behaviour. This view has, as we shall see, importantly delayed the study of specific profiles of dysfunction in childhood epilepsy.

The notion that childhood epilepsy leads to nonspecific dysfunction derives, at least in part, from the concept of cerebral plasticity. According to this concept, the immature brain possesses an exuberance of neurons and synapses that gradually undergo pruning in the process of differentiation during a critical period in development. ${ }^{73,74}$ Throughout childhood, the cerebral cortex undergoes significant changes characterized by increases in the size and complexity of nerve cells, progressive myelination, which continues into puberty, increased cortical fissuration required for refined control of behaviour and important changes in synaptic density. ${ }^{74,75}$ During this period, the brain is still flexible to modify its circuits and to establish new connections as part of functional compensation in the event of damage. ${ }^{76,77}$

Surgery outcome in childhood epilepsy has further contributed to the delay in research concerned with the description of specific patterns of dysfunction in children. Thus, studies assessing the neuropsychological and behavioural consequences of hemispherectomy, ${ }^{78}$ or callosotomy in children $^{79,80}$ have indicated that the symptoms following removal of cortical areas in adults are often attenuated or even absent in children. For instance, while adult split-brain patients are generally unable to cross-match objects or images presented to different hemispheres, children, having undergone the same type of surgery, do not manifest this interhemispheric disconnection syndrome. Indeed, in a long-term follow-up study conducted by our group, none of the 22 callosotomized patients that were 
operated before puberty exhibited the disconnection syndrome in the tactile modality whereas all of the patients older than 13 years showed the full expression of the syndrome. ${ }^{81}$ By the same token, removal of an entire hemisphere in young children does not seem to produce the same drastic deficits as in adult patients. ${ }^{82,83}$ This has been attributed to the plasticity of brain areas that have not yet reached functional maturity. Taken together, these results suggest that in a brain that still undergoes major maturational changes, other structures can take over the function of the damaged or removed area. This plasticity is more limited when the period of accelerated differentiation and specialization has passed.

\section{Distinct cognitive profiles of childhood epilepsy: the emerging view}

Although the developing brain may react differently to insult than the mature brain, it is now increasingly recognized that, just as in adults, different pediatric epilepsies have specific consequences. To the extent that the maturation of various brain areas follows different time tables, the regions that are undergoing the most vigorous maturational changes at a given time are the most vulnerable to insult. This can be demonstrated when a generalized convulsive disorder coincides with the development of a certain brain area. For instance, infantile spasms typically occur between three and eight months of age, that is at a period when the visual cortex undergoes rapid maturational changes. The most common long-term consequences of these generalized seizures are disturbances in the recognition of objects and faces. The affected children may develop autistic features as a result. ${ }^{84}$ If the epileptic event coincides with the maturation of the language areas, various types of language impairment may result. The Landau-Kleffner syndrome, ${ }^{85}$ a rare form of receptive aphasia, which tends to occur between the ages of three and eight years, is an example of such a disturbance.

Epileptic activity may also interfere with synaptic differentiation. The first two years of life are characterized by an important increase in synaptic density ${ }^{86}$ due to the vigorous formation of new synapses which starts at birth. This increase is followed by gradual synaptic elimination, induced by internal (neurotrophic) factors ${ }^{87}$ and interaction with the environment. The pruning process continues throughout childhood and adolescence and leads eventually to the greater refinement and functional efficiency of cortical areas. Abnormal excitatory input is likely to compete for the neural resources during the shaping and refinement of neural circuits, favoring the persistence of redundant connections, thus interfering with the establishment of functional specificity of the affected region(s). In support of this hypothesis, animal studies have shown that a single generalized convulsive event can result in the maintenance of synaptic connections that would otherwise be eliminated. ${ }^{88}$ Similarly, in a recent pilot study, ${ }^{89,90}$ we have shown that a single episode of status epilepticus in infants may produce a delay in the development of psychomotor and cognitive functions that are emerging at the time of the seizure. When retested three and nine months later, infants with onset before the age of 10 months manifested a developmental delay in all domains, except auditory-verbal functions, whereas infants older than 10 months at the time of the status epilepticus exhibited a significant delay in their language development with sparing of motor and visuoperceptual functions. Based on previous research ${ }^{86,88}$ there is reason to believe that these delays are the result of persistent synapses that would normally be eliminated during maturation. Investigations using electrophysiological measures and imaging techniques to further explore this hypothesis are presently underway in our laboratory.

Finally, it is now becoming apparent that various focal epilepsies in children have different cognitive expressions that are just beginning to be specified. For instance, Gadian et $\mathrm{al}^{91}$ found that left-sided pathology in children with intractable temporal epilepsy was associated with a decrease in verbal skills whereas right-sided pathology was associated with a loss of nonverbal functions. These findings are consistent with the pattern of lateralization of brain function and dysfunction observed in adults. ${ }^{55,92}$ In the same vein, we have recently conducted the first group study of children with frontal lobe epilepsy. ${ }^{93}$ Compared to children with temporal lobe epilepsy and generalized absence seizures, the frontal lobe group showed impairments in attention and executive functions (i.e., planning ability, impulse control, motor coordination) that are akin to those that have been previously reported for frontal-lobe lesioned adults. Similarly, distinct profiles for children with temporal epilepsy and different types of epilepsies have recently been described. ${ }^{49}$

In sum, neuropsychology of childhood epilepsy has evolved tremendously in the last decade. From a conception in which epilepsy was regarded as having diffuse cognitive and behavioural consequences, more recent research indicates that childhood epilepsy not only produces specific symptoms that are similar to those observed in adults but also that the emergence and the nature of these symptoms are related to the age at which cerebral maturation is being affected by the epileptic process. These findings stress the urgency for the development of neuroprotective agents that can arrest or even reverse the negative impact of abnormal bioelectric activity on the developing brain.

\section{REFERENCES}

1. Berg AT, Shinnar S. The risk of recurrence following a first unprovoked seizure: a quantitative review. Neurology 1991;41:965-972.

2. Camfield PR, Camfield CS, Dooley JM, et al. Epilepsy after a first unprovoked seizure in childhood. Neurology 1985;35:1657-1660.

3. Hauser WA, Rich SS, Lee JR, Annegers JF, Anderson VE. Risk of recurrence after two unprovoked seizures. $\mathrm{N}$ Engl $\mathrm{J}$ Med 1998;338:429-434.

4. Van Donselaar CA, Geerts AT, Meulstee J, Habbema JDF, Staal A. Reliability of the diagnosis of a first seizure. Neurology 1989;29:267-271.

5. Commission on classification and terminology of the International League Against Epilepsy. Proposal for revised classification of epilepsies and epileptic syndromes. Epilepsia 1989;30:389-399.

6. Roger J, Bureau M, Dravet C, et al. Epileptic Syndromes. London: John Libbey, 1992;75-88 and 189-200.

7. Camfield CS, Camfield PR, Gordon KE, Dooley JM, Smith BS. Predicting the outcome of childhood epilepsy - a population based study yielding a simple scoring system. J Pediatr 1993; 122:861-868.

8. Wirrell EC, Camfield CS, Camfield PR, Gordon K, Dooley J. Longterm prognosis of typical childhood absence epilepsy. Neurology 1996:47:912-918.

9. Singh R, Scheffer IE, Crossland K, Berkovic SF. Generalized 
epilepsy with febrile seizures plus: a common childhood-onset genetic epilepsy syndrome. Ann Neurol 1999; 45: 75-81.

10. De Silva M, MacArdle B, McGowan M, et al. Randomized comparative monotherapy trial of phenobarbitone, phenytoin, carbamazepine, or sodium valproate for newly diagnosed childhood epilepsy. Lancet 1996;347:709-713.

11. Canadian study group for childhood epilepsy. Clobazam has equivalent efficacy in carbamazepine and phenytoin as monotherapy for childhood epilepsy. Epilepsia 1998;39:952-959.

12. Verity CM, Hosking G, Easter DJ on behalf of The Pediatric EPITEG Collaborative Group. A multicentre comparative trial of sodium valproate and carbamazepine in pediatric epilepsy. Dev Med Child Neurol 1995;37:97-108.

13. Richens A, Davidson DLW, Cartlidge NEF, Easter DJ on behalf of the Adult EPITEG Collaborative Group. A multicentre trial of sodium valproate and carbamazepine in adult-onset epilepsy. $\mathbf{J}$ Neurol Neurosurg Psychiatry 1994;57:682-687.

14. Kalviainen R, Aikia M, Saukkonen AM, Mervaala E, Riekkinen P. Vigabatrin vs carbamazepine monotherapy in patients with newly diagnosed epilepsy. Arch Neurol 1995;52:989-996.

15. Chiron C, Marchand MC, Tran A, et al. Stiripentol in severe myoclonic epilepsy in infancy: a randomised placebo-controlled syndrome-dedicated trial. STICLO study group. Lancet 2000;356:1638-1642.

16. Kwan P, Brodie MJ. Early identification of refractory epilepsy. N Engl J Med 2000;342:314-319.

17. Camfield PR, Camfield CS, Gordon K, Dooley J. If a first antiepileptic drug fails to control a child's epilepsy, what are the chances of success with the next drug? J Pediatr 1997;131:821824.

18. Hardus P, Verduin WM, Engelsman M, et al. Visual field loss associated with vigabatrin: quantification and relation to dosage. Epilepsia 2001;42:262-267.

19. Pellock JM. Tiagabine (gabitril) experience in children. Epilepsia 2001;42 (Suppl 3):49-51.

20. Berg AT, Shinnar S. Relapse following discontinuation of antiepileptic drugs: meta-analysis. Neurology 1994;44:601-608.

21. Dooley JM, Gordon K, Camfield PR, et al. Discontinuation of anticonvulsant therapy in children free of seizures for 1 year. Neurology 1996;46:969-974.

22. Peters AC, Brouwer OF, Gerts AT, et al. Randomized prospective study of early discontinuation of AEDs in children with epilepsy. Neurology 1998;50:724-730.

23. Braathen G, Anderson T, Gylie H, et al. Comparison between one and three years of treatment in uncomplicated childhood epilepsy: a prospective study. 1 . Outcome in different seizure types. Epilepsia 1996:37;822-832.

24. Shinnar S, Berg AT. Does antiepileptic medication alter the prognosis of childhood seizures and prevent the development of chronic epilepsy. Sem Pediatr Neurol 1994;1:111-117.

25. Camfield PR, Camfield CS. Antiepileptic drug therapy: When is epilepsy truly intractable? Epilepsia 1996;37 (suppl 2):S60-S65.

26. Wirrell E, Camfield CS, Camfield PR, et al. Long-term psychosocial outcome in typical absence epilepsy: sometimes a wolf in sheep's clothing. Arch Pediatr Adol Med 1997;151:152158.

27. Camfield C, Camfield P, Smith B, Gordon K, Dooley J. Biologic factors as predictors of social outcome of epilepsy in intellectually normal children: a population-based study. J Pediatr 1993;122:869-873.

28. Jalava M, Sillanpaa M, Camfield CS, Camfield PR. Social adjustment and competence 35 years after onset of childhood epilepsy: a prospective controlled study. Epilepsia 1997;38:708715.

29. Banks GK, Regan KJ, Beran RG. The prevalence and direct costs of epilepsy in Australia. In: Beran RG, Pachlatko C. (Eds). Cost of Epilepsy: Proceedings of the 20th International Epilepsy Congress. Baden Germany: Ciba-Geigy Verlag 1995: 39-48.

30. Beran RG, Banks GK. Indirect costs of epilepsy in Australia. In: Beran RG, Pachlatko C. (Eds). Cost of Epilepsy: Proceedings of the 20th International Epilepsy Congress. Baden Germany: CibaGeigy Verlag 1995:49-54.
31. Cockerell OC, Hart YM, Sander JWAS, Shorvon SD. The cost of epilepsy in the United Kingdom: an estimation based on the results of two population-based studies. Epilepsy Res 1994; 18:249-260.

32. Gessner U, Sagmeister M, Horisberger B. The cost of epilepsy in Switzerland. Int J Health Sci 1993;4:121-128.

33. Murray MI, Halpern MT, Leppik IE. Cost of refractory epilepsy in adults in the USA. Epilepsy Res 1996;23:139-148.

34. Commision for the Control of Epilepsy and its Consequences. Economic cost of epilepsy. In: Plan for nationwide action on epilepsy, vol. IV, DHEW Publication no. 78-279. Washington, DC: NIH 1978:117-148.

35. Begley CE, Famulari M, Annegers JF, et al. The cost of epilepsy in the United States: an estimate from population-based clinical and survey data. Epilepsia 2000;41:342-351.

36. Begley CE, Annegers JF, Lairson DR, Reynolds TF. Methodological issues in estimating the cost of epilepsy. Epilepsy Res 1999;33: 39-55.

37. Hartunian NS, Smart CN, Thompson MS. The incidence and economic costs of cancer, motor vehicle injuries, coronary heart disease, and stroke: a comparative analysis. Am J Public Health 1980;70:1249-1260.

38. Adelman SM. The National Survey of Stroke. Economic impact. Stroke 1981;12:169-187.

39. Jacoby A, Buck D, Baker G, et al. Uptake and costs of care for epilepsy: findings from a U.K. regional study. Epilepsia 1998;39:776-786.

40. Wiebe S, Bellhouse DR, Fallahay C, Eliasziw M. Burden of epilepsy: the Ontario Health Survey. Can J Neurol Sci 1999;26:263-270.

41. Hauser WA, Annegers JF, Kurland LT. Prevalence of epilepsy in Rochester, Minnesota: 1940-1980. Epilepsia 1991;32:429-445.

42. Wiebe S, Gafni A, Blume WT, Girvin JP. An Economic Evaluation of Surgery for Temporal Lobe Epilepsy. J Epilepsy 1995;8:227-235.

43. Keene D, Ventureyra EC. Epilepsy surgery for 5- to 18-year-old patients with medically refractory epilepsy--is it cost efficient? Childs Nerv Syst 1999;15:52-54

44. Wiebe S, Blume WT, Girvin JP, Eliasziw M. A randomized, controlled trial of surgery for temporal-lobe epilepsy. N Engl J Med 2001; 345:311-318.

45. Vickrey BG, Hays RD, Engel J Jr, et al. Outcome assessment for epilepsy surgery: the impact of measuring health-related quality of life. Ann Neurol 1995;37:158-166.

46. Murray CJ, Lopez AD, Jamison DT. The global burden of disease in 1990: summary results, sensitivity analysis and future directions. Bull World Health Organ 1994; 72: 495-509.

47. Gross CP, Anderson GF, Powe NR. The relation between funding by the National Institutes of Health and the burden of disease. N Engl J Med 1999;340:1881-1887.

48. Shorvon SD. The lack of funds for clinical epilepsy research in the UK. J R Coll Physicians Lond 1991;25:31-32.

49. Jambaqué I, Lassonde M, Dulac O. The Neuropsychology of Childhood Epilepsy, New York: Plenum Press, New York, 2001.

50. Henriksen O. Education and epilepsy: assessment and remediation. Epilepsia 1990;31(suppl 4):S21-S25.

51. Hermann BP. Neuropsychological functioning and psychopathology in children with epilepsy. Epilepsia 1982;23:S45-S54.

52. Holdsworth L, Whitmore K. A study of children with epilepsy attending ordinary schools, their seizure patterns, progress and behaviour in school. Dev Med Child Neurol 1974;16:746-758.

53. Metz-Lutz ML, De Saint Martin A, Massa R, Hirsch E. Transitory cognitive disorders and learning impairment. In: Jambaqué I, Lassonde M, Dulac O (Eds), The Neuropsychology of Childhood Epilepsy, Plenum Press: New York. 2001, 159-169.

54. Luria AR. The Working Brain. New York: Penguin Books 1973.

55. Milner B. Interhemispheric differences in the localization of psychological processes in man. BMJ 1971; 27:272-277.

56. Rutter M, Graham P, Yule W. A Neuropsychiatric Study in Childhood. Philadelphia: J.B. Lippincott 1970.

57. Rutter M, Graham P, Yule W.A neuropsychiatric study in childhood clinics. Clinics in Developmental Medicine, London: SIMPwith Heinemann 1990;35-36. 
58. Stores G. School children with epilepsy at risk for learning and behavior problems. Dev Med Child Neurol 1978; 20, 502-508.

59. Ettinger AB, Weisbrot DM, Nolan EE, et al. Symptoms of depression and anxiety in pediatric epilepsy patients. Epilepsia 1998;39(6):595-599.

60. Hoare P. The development of psychiatric disorder among schoolchildren with epilepsy. Dev Med Child Neurol 1984; 26:3-13.

61. Jalava M, Sillanpäa M. Concurrent illness in adults with childhoodonset epilepsy. Epilepsia 1996;37:1155-1163.

62. Masur DM, Shinnar S. The neuropsychology of childhood seizure disorders. In: Segalowitz SJ , Rapin I. (Eds.). Handbook of Neuropsychology, Vol 7: Child Neuropsychology. Amsterdam: Elsevier, 1992;457-470.

63. Bourgeois BF. Antiepileptic drugs, learning, and behaviour in childhood epilepsy. Epilepsia 1998;39:91-92.

64. Bourgeois BF, Presnky AL, Palkes HS, Talent BK, Busch SG. Intelligence in epilepsy: a prospective study in children. Ann Neurol 1983;14: 438-444.

65. Seidenberg M. Academic achievement and school performance of children with epilepsy. In: Hermann BP, Seidenberg M (Eds.). Childhood Epilepsies: Neuropsychological, Psychosocial and Intervention Aspects. New York: John Wiley \& Sons 1989;105118.

66. Sturniolo MG, Galletti F. Idiopathic epilepsy and school achievement. Arch Dis Child 1994;70:424-428.

67. Yule W. Education achievement. In: Kulig BM, Meinardi H, Stores $\mathrm{G}$ (Eds). Epilepsy and Behaviour. Lisse/Berwyn: Swets \& Zeitlinger, 1980: 162-168.

68. Seidenberg M, Beck N, Geisser M, et al. Academic achievement of children with epilepsy. J Epilepsy 1986;1:23-30.

69. Sillanpää M. Social functioning and seizure status of young adults with onset of epilepsy in childhood. Acta Neurol Scand 1983; 96:1-81.

70. Aldenkamp AP, Alpherts WCJ, Dekker MJA, Overweg J. Neuropsychological aspects of learning disabilities in epilepsy. Epilepsia 1990; 31 (suppl 4):S9-S20.

71. Mitchell WG, Zhou Y, Chavez JM, Gusman BL. Reaction time, attention, and impulsivity in epilepsy. Pediatr Neurol 1992; 8:1924.

72. Vermeulen J, Kortstee SWAT, Alpherts WCJ, Aldenkamp AP. Cognitive performance in learning disabled children with and without epilepsy. Seizure 1994;3:13-21.

73. Changeux JP, Danchin A. Selective stabilization of developing synapses as a mechanism for the specification of neuronal networks. Nature 1976;264:705-721.

74. Huttenlocher PR, De Courten C, Garey LJ, van der Loos H. Synaptogenesis in human visual cortex- evidence for synapse elimination during normal development. Neurosci Lett 1982;33:247-252.

75. Changeux JP. L'Homme Neuronal. Paris: Fayard 1983.

76. Goldman-Rakic PS. Development and plasticity in primate frontal association cortex. In: Schmidt FO. (Ed). Organization of the Cerebral Cortex. Cambridge, Mass.: MIT Press, 1981: 69-97.
77. Kolb B, Nonneman AJ. Sparing of function in rats with early prefrontal cortex lesions. Brain Res 1978;151:135-148.

78. Bayard S, Lassonde M. Cognitive, sensory and motor adjustment to hemispherectomy. In: Jambaqué I, Lassonde M, Dulac O (Eds). The Neuropsychology of Childhood Epilepsy. New York: Plenum Press, 2001: 229-244.

79. Lassonde M, Sauerwein H, Geoffroy G, Décarie M. Effects of early and late transection of the corpus callosum in children. Brain 1986;109: 953-967.

80. Lassonde M, Sauerwein H, Chicoine AJ, Geoffroy G. Absence of disconnection syndrome in callosal agenesis and early callosotomy: brain reorganization or lack of structural specificity during ontology? Neuropsychologia 1991; 29:481-495.

81. Sauerwein HC, Lassonde M, Revol O, et al. Neuropsychological and psychosocial consequences of corpus callosotomy. In: Jambaqué I, Lassonde M, Dulac O (Eds). The Neuropsychology of Childhood Epilepsy. New York: Plenum Press, 2001: 245-256.

82. Stark RE, Bleilek K, Brandt J, Freeman J, Vining G. Speechlanguage outcomes of hemispherectomy in children and adults. Brain Lang 1995; 51:406-421.

83. Vargha-Khadem F, Isaacs EB, Papaleloudi H, Polkney CE, Wilson J. Development of language in six hemispherectomized patients. Brain 1991; 144:473-495.

84. Jambaqué I, Mottron L, Chiron C. Neuropsychological outcome in children with West syndrome: A "human model" for autism. In: Jambaqué I, Lassonde M, Dulac O (Eds.), The Neuropsychology of Childhood Epilepsy. New York: Plenum Press, 2001: 175-183.

85. Landau W, Kleffner A. Syndrome of acquired aphasia with convulsive disorder in children. Neurology 1957; 7:523-530.

86. Huttenlocher PR. Synaptic density in human frontal cortex. Developmental changes and effects of aging. Brain Res 1969; 163:195-205.

87. Cellerino A, Maffei L. The action of neurotrophins in the development and plasticity of the visual cortex. Prog Neurobiol 1996;49:53-61.

88. Grigonis AM, Murphy EH. The effects of epileptic activity on the development of callosal projections. Brain Res Dev Brain Res 1994;77:251-255.

89. Lassonde M. Neuropsychological and psychological impact of seizure disorders on children. Proceedings of the Johns Hopkins Advanced Studies in Medicine 2001; 1(4):166-172.

90. Roy H, Lussier F, Lortie A, Lassonde M. Cognitive consequences of status epilepticus in the young child. World Association for Infant Mental Health, 7th International Congress, Montreal 2000.

91. Gadian DG, Isaacs EB, Cross JH, et al. Lateralization of brain function in childhood revealed by magnetic resonance spectroscopy. Neurology 1996;46:974-977.

92. Milner B. Disorders of learning and memory after temporal lobe lesions in man. Clin Neurosurg 1972;19:521-546.

93. Hernandez MT, Sauerwein HC, De Guise E, et al. Neuropsychology of frontal lobe epilepsy in children. In: Jambaqué I, Lassonde M, Dulac O (Eds.), The Neuropsychology of Childhood Epilepsy. New York: Plenum Press, 2001: 103-111. 